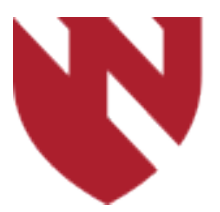

December 2019

\title{
The Financial Burden of the Urology Match: Room for improvement
}

Jinfeng Jiang

University of Nebraska Medical Center

Joshua S. Engelsgjerd

University of Nebraska Medical Center

Chad A. LaGrange

University of Nebraska Medical Center

Christopher M. Deibert

University of Nebraska Medical Center

Tell us how you used this information in this short survey.

Follow this and additional works at: https://digitalcommons.unmc.edu/gmerj

Part of the Higher Education Commons, Medical Education Commons, and the Urology Commons

\section{Recommended Citation}

Jiang, J., Engelsgjerd, J. S., LaGrange, C. A., , Deibert, C. M. The Financial Burden of the Urology Match: Room for improvement. Graduate Medical Education Research Journal. 2019 Dec 13; 1(1). https://digitalcommons.unmc.edu/gmerj/vol1/iss1/8

This Original Report is brought to you for free and open access by DigitalCommons@UNMC. It has been accepted for inclusion in Graduate Medical Education Research Journal by an authorized editor of DigitalCommons@UNMC. For more information, please contact digitalcommons@unmc.edu. 


\title{
The Financial Burden of the Urology Match: Room for improvement
}

\begin{abstract}
Abstract

Introduction/ Background - The Urology match remains highly competitive, but there is limited published data on the costs of the application process for contemporary applicants. This study aims to determine the financial burden of the Urological match and the effect it has on applicants.
\end{abstract}

Methods/ Materials - All applicants to the University of Nebraska Medical Center (UNMC) Urology Residency in the 2019 Urology match were invited to complete an anonymous, IRB approved online survey containing 16 questions on interview travel and costs, financial aid, and debt burden.

Results - Thirty-nine out of $183(21 \%)$ applicants responded to the survey. The median number of programs applied to was 87 (range 26 - 100). The median number of interviews offered was 17 (range 0 51) and the median number of interviews attended was 14 (range 0 - 27). The median interview expense was $\$ 6,0000$ (range $0-10,000$ ). Applicants reported the money came from a combination of medical student loans $(43 \%)$, family and friends (43\%), or from personal savings $(41 \%)$. To save money, $64 \%$ of applicants reported staying with family and friends on at least 1 interview and about $43 \%$ of applicants reported sharing a room with another applicant. Notably, $18 \%$ of applicants surveyed stated that they declined interviews due to cost. The median medical school debt of those surveyed was $\$ 57,500$.

Conclusions - At UNMC, applicants for the 2019 Urology interview cycle incurred a median monetary cost of $\$ 6,000$. With $18 \%$ of applicants stating that they declined interviews due to financial cost, there should be reform to the interview process to help lower costs to applicants and promote a successful match. Limiting total applications or coordinating same city interviews are two options to reduce cost.

\section{Abstract}

Introduction/ Background - The Urology match remains highly competitive, but there is limited published data on the costs of the application process for contemporary applicants. This study aims to determine the financial burden of the $U[A 1]$ rological match and the effect it has on applicants.

Methods/ Materials - All applicants to the University of Nebraska Medical Center (UNMC) Urology Residency in the 2019 Urology match were invited to complete an anonymous, IRB approved online survey containing 16 questions on interview travel and costs, financial aid, and debt burden.

Results - Thirty-nine out of $183(21 \%)$ applicants responded to the survey. The median number of programs applied to was 87 (range 26 - 100). The median number of interviews offered was 17 (range 0 51 ) and the median number of interviews attended was 14 (range 0 - 27). The median interview expense was $\$ 6,0000$ (range $0-10,000$ ). Applicants reported the money came from a combination of medical student loans (43\%), family and friends (43\%), or from personal savings $(41 \%)$. To save money, $64 \%$ of applicants reported staying with family and friends on at least 1 interview and about 43\% [A2] of applicants reported sharing a room with another applicant. Notably, 18\%[A3] of applicants surveyed stated that they declined interviews due to cost. The median medical school debt of those surveyed was $\$ 57,500[A 4]$.

Conclusions - At UNMC, applicants for the 2019 Urology interview cycle incurred a median monetary cost of $\$ 6,000$. With $18 \%$ of applicants stating that they declined interviews due to financial cost, there should be reform to the interview process to help lower costs to applicants and promote a successful match. Limiting total applications or coordinating same city interviews are two[A5] options to reduce cost. 
[A1]Check throughout - sometimes you capitalize Urology or Urological and other times you do not. Be consistent throughout entire paper. Either way is fine.

[A2]Don't start a sentence with a numeral - either spell it out or add to the previous sentence.

[A3]Change - you can also start a sentence with a transition like "Notably, 18\%..."

[A4]This seems low. Double check

[A5]Typically spell out numbers one-nine and then use numerals for 10 and up (except for measurements, dollar amounts, and others).

\section{Keywords}

Urology Match, Residency interviews, Interview costs, Early Match

\section{Creative Commons License}

c) (i) (8)

This work is licensed under a Creative Commons Attribution-Noncommercial-No Derivative Works 4.0 License. 
The Financial Burden of the Urology Match: Room for Improvement

Jinfeng Jiang ${ }^{1}$, Joshua S. Engelsgjerd', Chad A. LaGrange ${ }^{1}$, Christopher M. Deibert ${ }^{1}$

${ }^{1}$ University of Nebraska Medical Center, Department of Urology

https://doi.org/10.32873/unmc.dc.gmerj.1.1.008

\begin{abstract}
Introduction: The Urology match remains highly competitive, but there is limited published data on the costs of the application process for contemporary applicants. This study aims to determine the financial burden of the Urological match and the effect it has on applicants.
\end{abstract}

Methods: All applicants to the University of Nebraska Medical Center (UNMC) Urology Residency in the 2019 Urology match were invited to complete an anonymous, IRB approved online survey containing 16 questions on interview travel and costs, financial aid, and debt burden.

Results: Thirty-nine out of 183 (21\%) applicants responded to the survey. Applicants applied to 87 programs on average (range $26-100)$. The median number of interviews offered was 17 (range 0 - 51) and the median number of interviews attended was 14 (range 0 - 27). The median interview expense was $\$ 6,000$ (range $0-10,000$ ). Applicants reported the money came from a combination of medical student loans (43\%), family and friends (43\%), or from personal savings (41\%). To save money, $64 \%$ of applicants reported staying with family and friends on at least 1 interview and about $43 \%$ of applicants reported sharing a room with another applicant. Notably, $18 \%$ of applicants surveyed stated that they declined interviews due to cost. The median medical school debt of those surveyed was $\$ 57,500$.

Conclusions: At UNMC, applicants for the 2019 Urology interview cycle incurred a median monetary cost of $\$ 6,000$. With $18 \%$ of applicants stating that they declined interviews due to financial cost, there should be reform to the interview process to help lower costs to applicants and promote a successful match. Limiting total applications or coordinating same city interviews are two options to reduce cost.

\section{Introduction}

The rising cost of medical education places a significant burden on recently graduated medical students, with a national median medical school debt around $\$ 200,000$ per graduate. ${ }^{1}$ The costs related to the residency interview process further exacerbate this problem by adding to the debt from medical school. Applicants entering more competitive fields, such as Urology, incur even more costs. ${ }^{2}$ These costs may come from doing sub-internships at institutions far away from their home medical school, traveling across the country to as many interviews as possible, traveling back for second look visits after the interview process is completed, among others, all in an effort to increase the probability of matching in a highly selective subspecialty.

Though Urology is a competitive specialty, over the last 5 years there has been a greater success rate for US seniors to match. ${ }^{3}$ For example, in 2015 the US senior match rate was as low as $77 \%$; whereas, in the 2019 American Urological Association (AUA) match, $84 \%$ of applicants who submitted a rank list matched, with $91 \%$ of US seniors matched, which is the highest percentage in the last 5 years. Despite an increasing chance of US seniors to match into Urology, students are still spending large amounts of money to increase their chances of gaining a position.

Nikinow et al. surveyed 173 applicants from the 2014 Urology match and found that these applicants spent a median of $\$ 7,000$ on the match process. ${ }^{2}$ Applicants went on an median of 14 interviews with an median per interview cost of $\$ 500$. Furthermore, $95 \%$ of applicants went on at least 1 away rotation, while over $50 \%$ went on at least 2 away rotations. In total, the estimated amount of money spent by Urology applicants in the 2014 match process was about 3 million dollars.

Even though Urology is considered a highly competitive specialty, residency programs are expanding, which suggests that US senior medical students have the highest chance of matching into a position than we have seen in the last 7 years. Given this fact, we question whether there has been a change associated the costs of Urology residency interviews. If students are still spending a large amount of money for this process, what can be changed to lower these costs? To further evaluate the costs and burdens of the interview process, we surveyed 2019 AUA match applicants to the University of Nebraska Medical Center (UNMC) Urology Residency Program to evaluate the costs incurred and sources of financial assistance. We also evaluated ways in which the students attempted to save money and whether finances made an impact on decisions to interview at certain institutions.

\section{Materials and Methods}

In February 2019, after the 2019 AUA match was completed, all Urology applicants who applied to the UNMC Urology Residency Program were sent an email invitation to complete an anonymous survey on SurveyMonkey. This survey was approved by the UNMC institutional review board. Survey emails included informed consent, a survey purpose, and summary. All responses were anonymous, and participation was voluntary. The survey included a total of 16 questions. Applicants were asked to only complete the survey once. The survey included questions related to: (1) basic demographics, including gender, age, and region of medical school; (2) how many programs to which they applied; (3) how many interviews offers they received and attended; (4) the amount of money used on all interviews; (5) how they obtained money to cover interview expenses; (6) how they saved money (such as staying with family or friends); and (7) if they declined interviews due to cost or time constraints. Results were aggregated and averages and medians were calculated. Per applicant average cost was then extrapolated to all residents in the 2019 AUA Match to estimate total cost nationwide.

\section{Results}

In this survey on applicant costs to the 2019 Urology Match, 39 of 183 (21\%) completed the survey. Notably, 31 of 39 respondents were male (80\%). Using the AUA geographic regions, most of the applicants were from the South Central (23\%), North Central $(20 \%)$, or South Eastern (20\%) United States (Table 1). ${ }^{2}$ These applicants applied to a median of 87 (range 26-100) of the total 135 civilian Urology residency programs that participated. In return applicants received a median 17 interview offers (range 0-51) and attended a median of 14 program interviews $(0-27)$. Applicants on average spent $\$ 6,000$ $(0-10,000)$ during the interview process (Figure 1). Applicants reported that funds for interview travel were obtained from: student loans (43\%); family and friends (43\%); and/or personal savings (41\%). Most applicants used a single source of funding for their interview process, but $30 \%$ used 2 or more sources. The median total medical school debt burden was $\$ 57,500$ (0-100). 
To reduce spending, on average $64 \%$ of the applicants stayed with family or friends on at least 1 interview (range 0-15 interviews). Additionally, $43 \%$ shared a hotel or rented room with another applicant at the same interview. Importantly, 18\% of applicants declined at least 1 interview due to cost constraints alone.

\section{Discussion}

Medical school education costs continue to rise, seriously impacting medical students financially. For those students applying to competitive medical specialties, the residency interview process further increases the cost of medical education due to the limited number of spots per program and the perceived need to apply to more programs. In this study, we aimed to better understand the average costs of the Urology interview process, the influence of finances on this process, and the cost-saving measures undertaken by the applicants.

We found that an applicant to our Midwest regional program spent a median of $\$ 6,000$ on interview related costs. Extrapolating these costs to the 389 applicants who submitted a match list in the 2019 Urology match, a total of $\$ 2,334,000$ was spent on Urology interview costs. Applicants reported financing their interview expenses through student loans, money from friends and family, and personal savings. It was interesting to note that $30 \%$ of

\section{Table 1.}

Survey applicant demographics.

\begin{tabular}{ll} 
Demographics & Number \\
\hline Gender & $31(80 \%)$ \\
Males & $8(20 \%)$ \\
Females & \\
\hline Age & 32 \\
$25-30$ & 6 \\
$31-35$ & 0 \\
$36-40$ & 1 \\
$40+$ & \\
\hline Home Region & $4(10 \%)$ \\
Western & $9(23 \%)$ \\
South Central & $8(20 \%)$ \\
South Eastern & $8(20 \%)$ \\
North Central & $1(2 \%)$ \\
Mid-Atlantic & $1(2 \%)$ \\
New England & 0 \\
New York & $1(2 \%)$ \\
North Eastern & $7(18 \%)$ \\
International &
\end{tabular}

Urology applicants used 2 or more methods to fund their interview season, suggesting that one source of funding was not enough for all of the interview costs for some applicants. The costs of the interview process add on to their total graduate education debt (median $\$ 57,500)$.

Our statistics were similar to the statistics of the 2019 AUA match nationally. Respondents to our survey received an median 17 interviews while applying to 80 programs compared to 14.85 interviews for 71 applications nationally. ${ }^{2}$ Our findings on the average expenditures were comparable to other studies investigating the Urology interview process. For example, Nikonow et al. surveyed Urology applicants at 18 institutions and found the median cost of interviews to be $\$ 7,000$ in $2014 .{ }^{3}$ Studies have shown that competitive specialties like Urology are associated with higher interview costs. ${ }^{4}$ This is a double-edged sword for applicants, as competitive specialties generally have a smaller number of available spots per program, so applicants require more interviews to increase their chances of matching. At the same time, it is cost-prohibitive for some students who do not have the means to be able to fund the increased costs associated with more interviews. Specifically, $18 \%$ of respondents in our survey say that they turned down at least one interview due to the financial costs of attending. While Urology boasts a $91 \%$ match rate for US M.D. graduates in the 2019 AUA match, the number has been historically lower in the previous few years. By turning down interviews due to financial reasons, applicants potentially hurt themselves and their future career by running the risk of going unmatched.

We found that applicants tried to save money if possible with $64 \%$ of applicants reported staying with family and friends on at least one interview, and $43 \%$ of applicants reported sharing a room with another applicant to save on lodging costs. This shows that applicants are willing and interested in exploring options to reduce costs. Finding ways to help students with free or inexpensive lodging while on interviews would reduce the financial burden of interviewing. Various methods could be initiated to help interviewees find access to lodging. Lieber et al. conducted a study asking students interviewing in neurosurgery whether they would be interested in staying with local students and sharing transportation. ${ }^{5}$ The results were overwhelmingly positive for cost saving measures, with $85 \%$ of students willing to staying in dorms with local students. A formal centralized process could help students locate available lodging and could simplify the process. The AUA could organize this on their website or another 3rd party site, such as UrologyMatch.com, which already informally provides this, could sponsor the creation of such a resource to help facilitate lodging. ${ }^{6}$

Another possible way to lower interview costs is to use localized interviewing, whether by a preliminary web interview or for the programs themselves to come together regionally at a single location. Previous studies have shown that up to $60 \%$ of interview costs can be attributed to transportation. ${ }^{7}$ Canada has implemented a Urology fair as a solution for Urology residency interviews. ${ }^{8}$ Since 1994, all of the Canadian residency programs converge

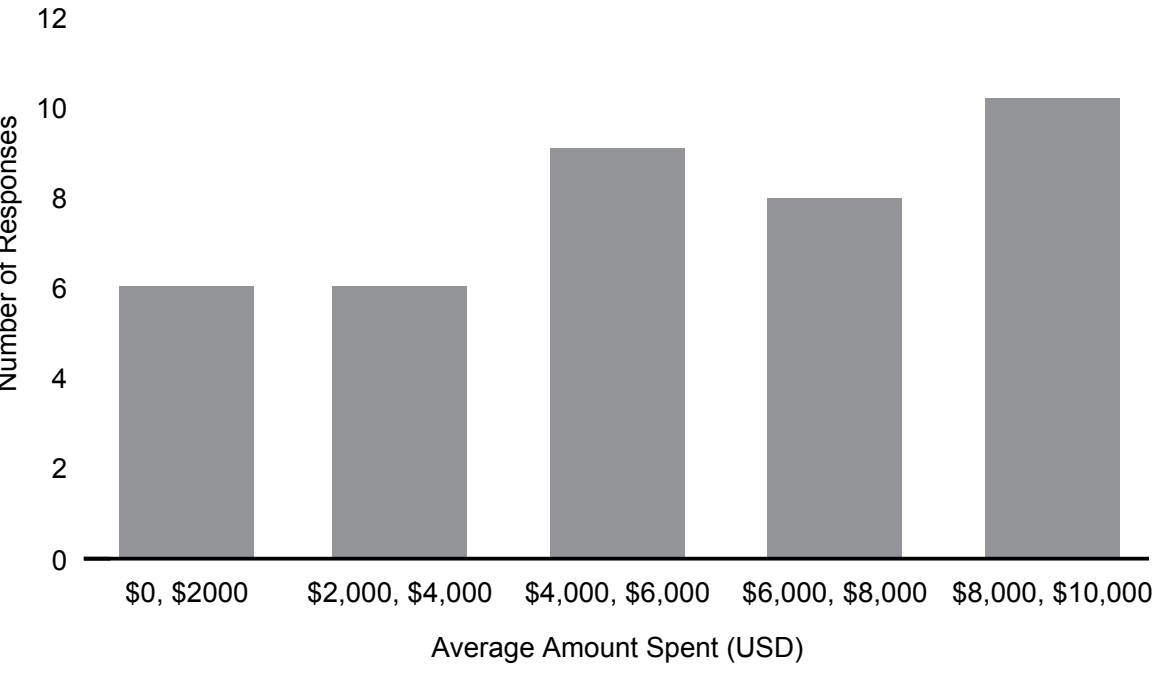

Figure 1. Total average expenditures per applicant on the 2019 Urology interview process (in U.S. dollars). 
at a central location to give potential residents an informational presentation and interview for their program. It was estimated that the average cost of interviewing using this format was $\$ 367$ (CAN) in 2001. Overwhelmingly, $96 \%$ of the students approved of this process, but $56 \%$ admitted to some adverse effect of not being physically able to visit the clinical site. It seems daunting to undertake such an initiative with the 10 -fold number of programs and larger pool of applicants in the US.

However, a similar program could perhaps be implemented in the AUA match, with regional Urology fairs separated by AUA region, serving as a cost cutting measure while accounting for the size of the application pool. Even coordinating interviews with multiple programs in the same city or region on back to back days would reduce travel costs. While $56 \%$ felt like the visit to the clinical site was important, second look events were frequently offered before the match to help applicants decide on the program without the pressure of the interview. However, the Society of

\section{References}

1 Association of American Medical Colleges (AAMC): 7 ways to reduce medical school debt. Available at https://news.aamc.org/medical-education/article/7ways-reduce-medical-school-debt/. Accessed March 2019

2 American Urological Association: Urology and Specialty Matches. Match Data: 2019. Available at https://www.auanet.org/education/urologyandspecialty-matches.cfm. Accessed December 2019

3 Nikonow TN, Lyon TD, Jackman SV, Averch TD. (2015). Survey of Applicant Experience and Cost in the Urology Match: Opportunities for Reform. The Journal of Urology, 194(4), 1063-1067

4 Fogel HA, Liskutin TE, Wu K, Nystrom L, Martin B, Schiff A. The Economic Burden of Residency Interviews on Applicants. Iowa Orthop J. 2018;38:9 15

5 Lieber BA, Wilson TA, Bell RS, Ashley WW, Barrow DL, Wolfe SQ. (2014). Gauging the feasibility of costsharing and medical student interest groups to reduce interview costs. Neurosurgical Focus, 37(5), E11.
Academic Urologists recently issued new policy prohibiting second looks. ${ }^{9}$

Web-based interviewing is another viable solution. New Mexico's Urology program implemented a trial of web-based interviewing and it showed significant decreases in interview costs. ${ }^{10}$ However, there was a decrease in interview satisfaction with the web-based only interview. A solution to this would be to use web-based interviews as an initial screen and supplement with a subsequent in-person interview. This would allow for applicants to get an inside glimpse of a program before committing to the costs of an interview.

There are several limitations to our study. Survey based data are limited by response bias, as those who responded to our survey may be motivated due to higher interview costs or other factors. Furthermore, the applicants who did not match may be less inclined to respond. The survey was limited to only those who applied to the UNMC Urology program, which was 43\% of AUA 2019 match applicants. Our sample size (39) is about $8 \%$ of the total applicants. Finally, the costs required applicant self-reporting, which might not accurately represent how much they spent.

\section{Conclusion}

Applicants surveyed reported spending a median of $\$ 6,000$ in the 2019 AUA match. Finances affected the number of interviews applicants attended with $18 \%$ responded saying that they had to decline at least one interview due to the financial costs. They also reported staying with friends and family or sharing lodging with other applicants to save money. The financial burden of the interview process hinders an applicant's ability to maximize their chances of matching and further novel efforts should be developed to help reduce the financial burden of the AUA match.
6 UrologyMatch.com. Available at: http://urologymatch. com/. Accessed on July 15, 2019.

7 Kerfoot BP, Asher KP and McCullough DL: Financial and educational costs of the residency interview process for urology applicants. Urology 2008; 71: 990

8 Grober ED, Matsumoto ED, Jewett MA, Chin JL. The Canadian urology fair: A model for minimizing the financial and academic costs of the residency selection process. Can J Surg. 2003;46(6):458-462.

9 Society of Academic Urologists: Resident Match Process. Available at https://sauweb.org/resources/ resident-match-process.aspx Accessed July 15, 2019

10 Shah SK, Arora S, Skipper B, Kalishman S, Timm TC, Smith AY. (2012). Randomized Evaluation of a Web Based Interview Process for Urology Resident Selection. The Journal of Urology, 187(4), 1380-1384. 